\title{
A ATUAÇÃO DA AUDITORIA INTERNA NA GOVERNANÇA PÚBLICA: UM ESTUDO BASEADO NA VISÃO DA ALTA ADMINISTRAÇÃO DAS UNIVERSIDADES PÚBLICAS FEDERAIS BRASILEIRAS
}

Douglas Renato Pinheiro 1

Eduardo de Camargo Oliva ${ }^{2}$

- Artigo recebido em: 25/07/2018 -- Artigo aceito em: 16/12/2019 .- Segunda versão aceita em: 28/04/2020

\section{RESUMO}

Esta pesquisa objetivou analisar a atuação da auditoria interna na governança das universidades públicas federais brasileiras, do ponto de vista da Alta administração, composta por Reitores, Vice-Reitores, Pró-Reitores de Administração e Pró-Reitores de Planejamento. Quanto à metodologia, realizouse uma pesquisa mista que consistiu de duas fases. Na primeira fase foi realizada uma pesquisa quantitativa descritiva com uma amostra de 33 universidades e, na segunda fase, uma pesquisa qualitativa, através da técnica de coleta de dados Focus Group. Os resultados apontam que a maioria da Alta administração concorda que a auditoria interna auxilia a universidade na execução de suas estratégias, possuindo uma atuação flexível e alinhada com os objetivos estratégicos da instituição, de forma a considerar a auditoria interna uma importante instância interna de apoio à governança da universidade.

Palavras-Chave: Governança Pública. Controle Público. Auditoria Interna. Auditoria.

1 Doutor em Administração pela Universidade Municipal de São Caetano do Sul (USCS). Professor na Universidade Municipal de São Caetano do Sul. Endereço: R. Santo Antonio, 50 Centro, São Caetano do Sul-SP, Brasil, CEP: 09521-160. E-mail: douglas.pinheiro@prof.uscs.edu.br https://orcid.org/0000-0001-7915-9134

2 Doutor em Administração pela Universidade de São Paulo. Professor Titular na Universidade Municipal de São Caetano do Sul (USCS). Endereço: R. Santo Antonio, 50 - Centro, São Caetano do Sul-SP, Brasil, CEP: 09521-160. E-mail: eduardo.oliva@prof.uscs.edu.br https://orcid.org/0000-0002-7454-3759

Editora responsável pela aprovação do artigo: Drª Bruna Camargos Avelino Editora responsável pela edição do artigo: Drª Bruna Camargos Avelino 


\title{
THE PERFORMANCE OF INTERNAL AUDITING IN PUBLIC GOVERNANCE: A STUDY BASED ON THE VIEW OF HIGH ADMINISTRATION OF BRAZILIAN FEDERAL PUBLIC UNIVERSITIES
}

\begin{abstract}
This research aimed to analyze the performance of internal auditing in the governance of Brazilian federal public universities, from the point of view of senior management, composed of Rectors, Vice Rectors, Pro-Rectors of Administration and Pro-Rectors of Planning. As for the methodology, a mixed research was carried out, which consisted of two phases. In the first phase, a descriptive quantitative research was carried out with a sample of 33 universities and, in the second phase, a qualitative research using the Focus Group data collection technique. The results indicate that the majority of the top management agrees that the internal audit assists the university in the execution of its strategies, having a flexible and aligned action with the strategic objectives of the institution, in order to consider the internal audit an important internal support governance of the university.
\end{abstract}

Keywords: Public Governance. Public Control. Internal Audit. Risk Based Audit.

\section{INTRODUÇÃO}

Os diversos casos de corrupção envolvendo os setores privado e público, nas três esferas de governo: federal, estadual e municipal, tem proporcionado um cenário de instabilidade e incertezas para o Brasil. A operação Lava Jato da Polícia Federal respondeu aos anseios dos brasileiros no tocante às medidas de combate à corrupção e, ao longo dos últimos anos, a operação revelou vários esquemas de corrupção, colocando na prisão grandes empresários, banqueiros e políticos. A corrupção é ruim em todos os aspectos, mas principalmente porque reduz a efetividade dos gastos públicos, de forma que os recursos financeiros recolhidos da população, através dos tributos, não são plenamente utilizados no fornecimento de bens e serviços públicos.

Nesse cenário, há uma preocupação crescente do setor público brasileiro em criar controles eficazes e eficientes, com a finalidade de inibir a corrupção, tais como procedimentos padronizados e normativos gerenciais, delegações de autoridade e competência, segregação de funções, mapeamento dos riscos que envolvem os processos estratégicos, adequação e economicidade dos sistemas de controle interno, entre outros (Castro, 2015).

De acordo com Peter e Machado (2014), a gestão pública possui três instâncias de controle: o controle interno, o controle externo e o controle social. O controle interno é exercido no âmbito da entidade ou por órgãos da própria administração pública, com o objetivo de prevenção e orientação; o controle externo é realizado por órgãos que não fazem parte da gestão administrativa, e por isso, possuem maior independência funcional, como por exemplo, o controle realizado pelos tribunais de contas, conforme preconiza o Art. 71 da Constituição Federal de 1988; e o controle social, que é exercido pelos cidadãos. 
$\mathrm{Na}$ busca da melhor alocação dos recursos públicos, a auditoria representa um importante instrumento de controle do Estado, não apenas colaborando para a evidenciação dos desperdícios na utilização dos recursos, da improbidade administrativa, da inobservância às normas e leis, mas, principalmente, antecipando-se a essas situações no intuito de garantir os resultados planejados, com destaque para os impactos e benefícios sociais advindos (Chaves, 2011).

De acordo com Batista (2011), há dois tipos de auditoria pública em relação à natureza de sua atuação: auditoria externa e auditoria interna.

A auditoria externa, também chamada de auditoria independente, é uma auditoria realizada por uma instituição externa e sem vínculos com a entidade auditada, e tem como objetivo precípuo, a análise e avaliação das demonstrações contábeis da organização (Silva, 2012).

A auditoria interna é uma atividade realizada por um profissional interno à organização, e que possui como objetivos a realização de auditorias preventiva, operacional e corretiva, fornecendo além de recomendações visando à melhoria dos resultados da instituição, a proteção dos bens e direitos da entidade contra erros e fraudes (Batista, 2011).

Segundo o Instituto dos Auditores Internos do Brasil - IIA Brasil e, em conformidade com a International Professional Practices Framework - IPPF, estrutura internacional de práticas profissionais de auditoria interna promulgadas pelo Institute of Internal Auditors Global - IIA Global, a missão das unidades de auditoria interna consiste em: "Aumentar e proteger o valor organizacional, fornecendo avaliação (assurance), assessoria (advisory) e percepção (insight) baseadas em risco" (IIA Brasil, s.d.).

Dessa forma, as normas internacionais estabelecem que a atividade de auditoria interna deve avaliar e sugerir recomendações adequadas para o aperfeiçoamento do processo de governança, visando: a promoção da ética e dos valores organizacionais, a gestão eficaz e a prestação de contas, a transmissão de informações aos setores responsáveis em relação aos riscos e controles, bem como, a coordenação de atividades e de comunicação entre a gestão, o conselho e os auditores internos e externos (IIA, 2012). Nesse contexto, o presente artigo tem como objetivo analisar a atuação das auditorias internas na governança das universidades públicas federais brasileiras, do ponto de vista da Alta Administração.

\section{REVISÃO DA LITERATURA}

Neste capítulo, desenvolveu-se o referencial teórico do artigo, que perpassa a governança pública e a atuação da auditoria interna.

\subsection{Governança Pública}

Segundo o Word Bank (em TCU, 2014), "governança diz respeito às estruturas, funções, processos e tradições organizacionais que visam garantir que as ações planejadas (programas) sejam executadas de tal maneira que atinjam seus objetivos e resultados de forma transparente". 
A Atuação da Auditoria Interna na Governança Pública: um Estudo Baseado na Visão da Alta Administração das Universidades Públicas Federais Brasileiras

Ressalta-se, nesses termos, que há distinção do conceito de governança pública e privada. De modo geral, no setor privado, a governança está relacionada com a estrutura organizacional e a prestação de contas para os acionistas. No setor público, a expressão governança revela diferentes perspectivas em decorrência da dimensão e complexidade das entidades governamentais (Streit \& Klering, 2004).

Enquanto no setor privado os agentes envolvidos são os executivos contratados pelo principal, representado pelos acionistas ou proprietários das empresas, no setor público, os cidadãos assumem a condição de principal, e os governantes e dirigentes públicos, seus agentes (Cavalcante \& De Luca, 2013).

Verifica-se que os objetivos do principal e do agente, no setor privado e público, também são diferentes. Enquanto, no setor privado, o principal busca a maximização de riqueza, no setor público o seu principal objetivo é o bem-estar social e a maximização de valor para a sociedade (Cavalcante \& De Luca, 2013).

Em relação aos objetivos do agente, e de acordo com Cavalcante e De Luca (2013), no setor privado ocorre uma vigorosa busca pelo reconhecimento e remuneração, já no setor público, os interesses dos agentes são políticos e administrativos.

Nesse contexto, e em comparação ao setor privado, os propósitos e os resultados gerados pelo setor público são menos visíveis e mensuráveis, o sistema de controle é mais disperso e os diversos objetivos dos agentes são muitas vezes conflitantes (Streit \& Klering, 2004).

O monitoramento do comportamento dos agentes pelo principal, com o objetivo de reduzir a assimetria informacional, é realizado tanto por mecanismos internos de governança, como por exemplo, através da atuação das auditorias internas e do conselho de administração ou órgãos de atribuições equivalentes, quanto por mecanismos externos, através do controle social (cidadãos) e controle externo (tribunais de contas) no setor público (Cavalcante \& De Luca, 2013).

Dessa forma, o sistema de governança em órgãos e entidades públicas é composto de quatro diferentes instâncias: as instâncias externas de governança, as instâncias externas de apoio à governança, as instâncias internas de governança e as instâncias internas de apoio a governança (TCU, 2014).

O Controle externo, a cargo do Congresso Nacional, será exercido com o auxílio do Tribunal de Contas da União, conforme Art. 71 da Constituição Federal de 1988, e representa instância externa de governança responsável pela fiscalização, regulação e controle, agindo de forma autônoma e independente no setor público.

As instâncias externas de apoio à governança são responsáveis pela auditoria e monitoramento independente, realizados pelas auditorias independentes e o controle social organizado (TCU, 2014).

Os conselhos de administração ou equivalentes e a Alta administração são os responsáveis por definir e avaliar as estratégias e as políticas que atendam ao interesse público, servindo de ligação entre principal e agente, posicionando-se como instâncias internas de governança (TCU, 2014). 
Segundo Rodrigues e Mendes (2004), a gestão estratégica exercida pelo conselho de administração estabelece as estratégias visando a horizontes de longo prazo, aproveitando as oportunidades e colocando em prática os projetos de expansão que irão alavancar o valor da empresa.

Verifica-se que o conselho de administração é um dos principais mecanismos para alinhamento dos interesses da sociedade (cidadãos e outras partes interessadas) e a Alta administração no sistema de governança em órgãos e entidades da administração pública (TCU, 2014).

Como instrumento da gestão democrática, e conforme demonstrado na Figura 1 a seguir, as universidades públicas federais dispõem de Conselhos Superiores, que atuam de forma consultiva, deliberativa, normativa e fiscalizadora.

\begin{tabular}{|c|c|c|}
\hline Conselhos Superiores & Composição & Principais atividades \\
\hline $\begin{array}{l}\text { Conselho Universitário - } \\
\text { CONSUNI } \\
\text { (Função consultiva, } \\
\text { deliberativa, normativa } \\
\text { e fiscalizadora). }\end{array}$ & $\begin{array}{l}\text { 1. Docentes, servidores e } \\
\text { discentes eleitos por seus } \\
\text { pares; } \\
\text { 1.1 o cONSUNI será } \\
\text { formado por um mínimo } \\
\text { de } 70 \% \text { de membros do } \\
\text { corpo docente (Lei no } \\
9.394 \text { de } 20 \text { de dezembro } \\
\text { de 1996). } \\
\text { 2.Pró-Reitores indicados } \\
\text { pelo Reitor e aprovados } \\
\text { pelo Conselho; } \\
\text { 3.Representação externa; }\end{array}$ & $\begin{array}{l}\text { 1. Diretrizes estratégicas; } \\
\text { 2. Aprovação de estatuto e } \\
\text { regimento geral da universidade; } \\
\text { 3. Aprovação dos regimentos das } \\
\text { unidades acadêmicas; } \\
\text { 4.Decisão sobre intervenção em } \\
\text { qualquer unidade acadêmica; } \\
\text { 5. Aprovação e criação de Centros, } \\
\text { Departamentos, Pró-Reitorias etc. } \\
\text { 6. Apuração de atos de } \\
\text { responsabilidade do Reitor; } \\
\text { 7. Aprovação da prestação de } \\
\text { contas da gestão; entre outras } \\
\text { atividades. }\end{array}$ \\
\hline $\begin{array}{l}\text { Conselho de } \\
\text { Administração - } \\
\text { CONSAD } \\
\text { (Função consultiva, } \\
\text { deliberativa e } \\
\text { normativa) }\end{array}$ & $\begin{array}{l}\text { 1. Membros internos da } \\
\text { comunidade universitária } \\
\text { com competências } \\
\text { definidas. }\end{array}$ & $\begin{array}{l}\text { 1. Diretrizes orçamentárias e } \\
\text { distribuição interna do orçamento; } \\
\text { 2. Concurso técnico-administrativo; } \\
\text { 3. Criação de órgãos administrativos; } \\
\text { 4. Alienação de Bens Patrimoniais } \\
\text { Imóveis. }\end{array}$ \\
\hline $\begin{array}{l}\text { Conselho de Ensino, } \\
\text { Pesquisa e Extensão - } \\
\text { CONSEPE } \\
\text { (Função consultiva, } \\
\text { deliberativa e } \\
\text { normativa) }\end{array}$ & $\begin{array}{l}\text { 1. Membros internos da } \\
\text { comunidade universitária } \\
\text { com competências } \\
\text { definidas. }\end{array}$ & $\begin{array}{l}\text { 1.Concurso docente; } \\
\text { 2. Criação de cursos de graduação, } \\
\text { mestrado e doutorado; } \\
\text { 3. Normas sobre matéria de ensino, } \\
\text { pesquisa, extensão, revalidação de } \\
\text { diplomas, etc. } \\
\text { 4. Redistribuição docente. }\end{array}$ \\
\hline $\begin{array}{l}\text { Conselho de Curadores } \\
\text { (Função fiscalizadora) }\end{array}$ & $\begin{array}{l}\text { 1. Membros internos da } \\
\text { comunidade universitária } \\
\text { com competências } \\
\text { definidas; } \\
\text { 2. Membros externos. }\end{array}$ & $\begin{array}{l}\text { 1. Acompanhamento e fiscalização } \\
\text { das atividades de natureza } \\
\text { econômica, financeira, contábil e } \\
\text { patrimonial. }\end{array}$ \\
\hline
\end{tabular}

Figura 1 - Conselhos Superiores, composição e principais atividades

Fonte: Elaborada pelos autores. 
A Atuação da Auditoria Interna na Governança Pública: um Estudo Baseado na Visão da Alta Administração das Universidades Públicas Federais Brasileiras

A auditoria interna, ouvidoria, conselho fiscal, comissões e comitês integram as instâncias internas de apoio à governança e realizam a comunicação entre partes interessadas internas e externas à administração (TCU, 2014).

\title{
2.2 Auditoria Interna
}

De acordo com Institute of Internal Auditors Research Foundation (IIARF, 2009). A auditoria interna é uma atividade global, praticada no setor privado e no setor público, e em função dos diversos ambientes ao redor do mundo, e dos diferentes propósitos, tamanho e estrutura das organizações, suas capacidades e sofisticação sofrem variações.

Na Administração Pública, a Secretaria Federal de Controle Interno - SFC, vinculada à Controladoria Geral da União - CGU, em sua Instrução Normativa nº 01, de 06 de abril de 2001, menciona:

\begin{abstract}
A auditoria interna constitui-se em um conjunto de procedimentos, tecnicamente normatizados, que funciona por meio de acompanhamento indireto de processos, avaliação de resultados e proposição de ações corretivas para os desvios gerenciais da entidade à qual está vinculada. Os trabalhos de auditoria interna são executados por unidade de auditoria interna, ou por auditor interno, especialmente designado para a função, e tem como característica principal o assessoramento à alta administração da entidade, buscando agregar valor à gestão (BRASIL, 2001).
\end{abstract}

A auditoria interna é vista como um órgão de controle que deve possuir total independência no desenvolvimento de suas atividades, de forma a proteger a gestão contra erros, fraudes, desperdícios e outros riscos que possam afetar a criação de valor organizacional (Sá, 2002).

Marçola (2011, p. 79) aduz que: "A auditoria interna é uma área diretamente vinculada à Alta administração e que, com autonomia e independência, promove a verificação dos controles internos de todos os setores da organização".

Quanto à vinculação das auditorias internas das entidades da Administração Indireta do Poder Executivo Federal, o parágrafo $8^{\circ}$, Seção I, Capítulo X da Instrução Normativa n ${ }^{\circ}$ 01, de 06 de abril de 2001 determina:

(...) a unidade de auditoria interna ou auditor interno deverá estar subordinada ao conselho de administração ou a órgão de atribuições equivalentes. Caso a entidade não conte com conselho de administração ou órgão equivalente, a auditoria interna ou o auditor interno subordinar-se-á diretamente ao dirigente máximo da entidade, vedado delegar a vinculação a outra autoridade. Essa vinculação tem por objetivo proporcionar à unidade de auditoria interna um posicionamento suficientemente elevado de modo a permitir-lhe desincumbir-se de suas responsabilidades com abrangência e maior independência, $\left(\mathrm{INn}^{\circ} 1,2016\right)$.

Em relação a função da auditoria interna, e de acordo com o Art. $2^{\circ}$, inciso III, da Instrução Normativa Conjunta ${ }^{\circ} 1$, de 10 de maio de $2016\left(\operatorname{INn}^{\circ} 1,2016\right)$, do Ministério da Economia e da Controladoria Geral da União: 
Compete às auditorias internas oferecer avaliações e assessoramento às organizações públicas, destinadas ao aprimoramento dos controles internos, de forma que controles mais eficientes e eficazes mitiguem os principais riscos de que os órgãos e entidades não alcancem seus objetivos (INnº 1,2016$)$.

Os serviços de avaliação (assurance) necessitam ser suficientemente abrangentes com o objetivo de fornecer uma segurança razoável em nível corporativo de que os processos e controles organizacionais funcionam e são adequados para satisfazer os objetivos da organização (IIARF, 2009).

Os trabalhos de consultoria (consulting) têm como objetivo agregar valor à gestão através da análise de uma situação e/ou fornecimento de uma orientação ou aconselhamento para a alta Administração. Nessa atividade, os auditores não devem assumir a responsabilidade pela gestão (IIARF, 2009).

De acordo com Batista (2011, p.28), "A consultoria consiste em assistir e contribuir, continuamente, para ajustes ou suprimento de deficiências internas na gestão contábil, fiscal, tributária, jurídica, financeira, patrimonial e de pessoal".

A auditoria interna é uma atividade que visa fortalecer o controle interno da instituição, fornecendo meios à gestão para averiguar o andamento do sistema contábil, a coerência legal dos procedimentos, a gestão administrativa, o controle patrimonial, os procedimentos adotados e o cumprimento ou não das políticas definidas pela Alta administração (Batista, 2011).

Ressalta-se que as auditorias internas na Administração Pública constituem a terceira instância de defesa, conforme menciona o art. $2^{\circ}$ inciso III da Instrução Normativa Conjunta $\mathrm{n}^{\circ} 1$, de 10 de maio de $2016\left(\mathrm{INn}^{\circ} 1,2016\right)$ do Ministério da Economia e da Controladoria Geral da União:

As auditorias internas no âmbito da Administração Pública se constituem na terceira linha ou camada de defesa das organizações, uma vez que são responsáveis por proceder à avaliação da operacionalização dos controles internos da gestão (primeira linha ou camada de defesa, executada por todos os níveis de gestão, dentro da organização) e da supervisão dos controles internos (segunda linha ou camada de defesa, executada por instâncias específicas, como comitês de risco e controles internos), (INnº 1,2016$)$.

Para alcançar as suas finalidades, e de acordo com o Institute of Internal Auditors Research Foundation - IIARF (2009), a auditoria interna deve ser realizada por profissionais que tenham uma compreensão profunda da organização, sua cultura organizacional, seus sistemas, processos, e que estejam em conexão com as normas internacionais para a prática profissional de auditoria interna.

Nesse contexto, a auditoria interna representa um dos pilares da boa governança no setor público e, ao proporcionar avaliações objetivas e imparciais em relação à gestão dos recursos públicos, os auditores contribuem para assegurar a integridade nas organizações e melhorar o desempenho das operações (Marques, 2014).

No entanto, apesar da importante contribuição das unidades de auditoria interna para a governança das organizações, Marçola (2011) menciona que a falta de interesse na implementação dessas unidades no setor público decorre do total desconhecimento por parte do gestor público da missão e dos objetivos das auditorias internas, e que de forma equivocada, visualiza a auditoria interna 
composta por Reitores, Vice-Reitores, Pró-Reitores de Administração e Pró-Reitores de Planejamento, com o objetivo geral de verificar e analisar a atuação da auditoria interna na governança das universidades públicas federais brasileiras.

Os dados do levantamento de campo foram coletados de forma presencial, mediante participação em reuniões, nos meses de novembro e dezembro de 2016, com os Pró-Reitores de Administração e Pró-Reitores de Planejamento, no $4^{\circ}$ Fórum Nacional de Pró-Reitores de Planejamento e de Administração das Instituições Federais de Ensino Superior - FORPLAD, que foi organizado pela Universidade Federal do Sul da Bahia (UFSB), entre os dias 07 e 11 de novembro de 2016 na cidade de Porto Seguro - BA, e com os Reitores e Vice-Reitores na Associação Nacional de Dirigentes das Instituições Federais de Ensino Superior - ANDIFES nos dias 14 e 15 de dezembro de 2016, em Brasília - DF.

Obteve-se o retorno do questionário de 10 (dez) Reitores, 2 (dois) ViceReitores, 16 (dezesseis) Pró-Reitores de Administração e 5 (cinco) Pró-Reitores de Planejamento, totalizando 33 universidades respondentes, contemplando as cinco regiões do país, sendo $30,30 \%$ de universidades da região Sudeste, $27,27 \%$ da região Nordeste, $24,24 \%$ da região Sul, $15,15 \%$ da região Norte e 3,03\% da região Centro-Oeste.

Com a finalidade de medir a intensidade das opiniões da Alta administração das universidades públicas federais em relação ao objeto da pesquisa, de maneira mais objetiva possível, foram construídas afirmativas e escalas sociais ordinais, escala tipo Likert que, em essência, segundo Gil (2010, p. 144):

\begin{abstract}
Pede-se a certo número de pessoas que manifestem sua concordância ou discordância em relação a cada um dos enunciados, segundo a graduação: concorda muito (5), concorda um pouco (4), indeciso (3), discorda um pouco (2), discorda muito (1). Analisam-se as respostas para verificar quais os itens que discriminam mais claramente entre os que obtêm resultados mais elevados e os que obtêm resultados baixos na escala total.
\end{abstract}

Após a análise e interpretação estatística dos dados, foi realizado um Focus Group, que correspondeu à segunda fase da pesquisa. Segundo Oliveira e Freitas (1998), o Focus Group é uma entrevista realizada em grupo, no qual corresponde a uma técnica de pesquisa qualitativa geralmente associada a outras técnicas de coleta de dados. O Focus Group, ao suceder um método quantitativo, contribui para a interpretação e o fornecimento de informações adicionais em relação aos resultados obtidos.

O grupo focal contou com a participação do pesquisador, que fez as anotações, reflexões e transcrição dos dados produzidos; do moderador, que foi responsável pela dinâmica da entrevista em grupo e, com a participação voluntária de 12 Pró-Reitores de Administração, abrangendo as cinco regiões do país, que foram identificados como PRA 1 - região, PRA 2 - região e PRA n... região do país.

O Focus Group ocorreu em março de 2017, em uma das salas de reuniões do Mar Hotel Recife, durante o Fórum Nacional de Pró-Reitores de Administração e Planejamento - FORPLAD, promovido pela Universidade Federal de Pernambuco - UFPE, em Recife - PE. 
A Atuação da Auditoria Interna na Governança Pública: um Estudo Baseado na Visão da Alta Administração das Universidades Públicas Federais Brasileiras

Para a análise dos dados do grupo focal, utilizou-se a técnica da análise do discurso. De acordo com Caregnato e Mutti (2006, p. 684), "Na análise do discurso, a linguagem não é transparente, mas opaca, por isso, o analista de discurso se põe diante da opacidade da linguagem". Nesse sentido, a análise do discurso buscou compreender os sentidos dos discursos produzidos pelos sujeitos da pesquisa.

\section{APRESENTAÇÃO E ANÁLISE DOS RESULTADOS}

Do total de respondentes da pesquisa, 48,48\% ocupam o cargo de PróReitor de Administração, 30,30\% dos respondentes ocupam o cargo de Reitor, 15, 15\% o cargo de Pró-Reitor de Planejamento e 6,07\% ocupam o cargo de ViceReitor.

Além do cargo, os respondentes informaram o tempo de exercício no cargo e, de acordo com a pesquisa, 33,33\% ocupam o cargo entre 1 a 3 anos, $18,18 \%$ há menos de 1 ano, $12,13 \%$ entre 4 a 6 anos, $18,18 \%$ entre 7 a 9 anos $e$ 18,18\% ocupam o cargo há mais de 9 anos.

Após a identificação dos respondentes, realizou-se a classificação das universidades pesquisadas em grande, médio e pequeno porte. Para tanto, os pesquisadores utilizaram-se de uma distribuição normal com o seguinte critério: $25 \%$ do total de universidades públicas federais com os maiores valores orçamentários foram classificadas como universidades de grande porte, o que corresponde a um valor orçamentário anual igual ou superior a $R \$ 878.596 .891,00$. Por outro lado, $25 \%$ do total das universidades públicas federais com os menores valores orçamentários foram classificadas como universidades de pequeno porte, - que corresponde a um valor orçamentário anual igual ou inferior a $R \$$ 219.873.257,00 e as universidades restantes, que representam os outros $50 \%$, foram classificadas como universidades de médio porte, o que corresponde às universidades com montante orçamentário entre $R \$ 219.873 .257,01$ a $R \$$ 878.596.890,99.

Diante dessa classificação, verificou-se que $42,42 \%$ das universidades respondentes são de grande porte, $30,30 \%$ são universidades de médio porte e $27,28 \%$ são universidades de pequeno porte.

Em relação à governança das universidades públicas federais e, de acordo com os respondentes da pesquisa, $63,6 \%$ das universidades públicas federais não possuem o Comitê de Governança, Riscos e Controles, consoante determinação da Instrução Normativa Conjunta n 01, do dia 10 de maio de 2016, proveniente do Ministério do Planejamento, Orçamento e Gestão - MP e da Controladoria Geral da União - CGU. Esse comitê é composto pelo dirigente máximo e pelos dirigentes das unidades a ele diretamente subordinadas, com o apoio do Assessor Especial de Controle Interno.

Nesse contexto, o resultado apontou que, aproximadamente, $64 \%$ das universidades públicas federais não estão em conformidade com a Instrução Normativa Conjunta $\mathrm{n}^{\circ}$ 01, de 10 de maio de 2016 e, dessa forma, evidenciou-se uma situação de fragilidade no sistema de governança dessas universidades, tendo em vista que uma das principais competências do Comitê de Governança, Riscos e Controles é o estabelecimento de diretrizes para a institucionalização da gestão de riscos na universidade. Em decorrência desse resultado, identificou-se 
que $66,7 \%$ da Alta administração não realiza a gestão de riscos na instituição. Além disso, constatou-se que $30,3 \%$ das universidades pesquisadas realizam a gestão de riscos há menos de 3 anos, o que evidencia o estágio embrionário da gestão de riscos dessas universidades.

De acordo com o resultado da pesquisa quantitativa, os Pró-Reitores de Administração e de Planejamento apontaram para a inexistência de gestão de riscos nas universidades. Esse tema foi abordado no grupo focal e os Pró-Reitores argumentaram que essa questão teve como base de resposta uma gestão de riscos estruturada de forma sistemática, organizada e consolidada, conforme recomendação do Committee of Sponsoring Organizations (COSO, 2004) e determinação da Instrução Normativa Conjunta $n^{\circ}$ 01, de 10 de maio de 2016, do Ministério do Planejamento, Orçamento e Gestão - MP e da Controladoria Geral da União - CGU, conforme demonstrado na citação a seguir:

\begin{abstract}
"O conceito de gestão de riscos é muito amplo, e as universidades, de um modo geral, possuem um mapeamento dos riscos, já que existem controles internos em praticamente todas as áreas para minimizar os riscos. Porém, o conceito, a forma e os procedimentos de gestão de riscos determinados pela recente Instrução Normativa Conjunta $\mathrm{n}^{\circ} 01$ do Ministério do Planejamento e da CGU exigem uma estrutura apropriada, um aprofundamento dos processos existentes e, para que isso aconteça, as universidades públicas precisam avançar" (PRA 1 região Nordeste).
\end{abstract}

Não obstante, os Pró-Reitores de Administração afirmaram que está em andamento à implementação de uma estrutura de gestão de riscos nas universidades públicas federais que avalie de forma integrada os riscos, bem como fomente o monitoramento contínuo do ambiente de riscos, tendo em vista que a Instrução Normativa Conjunta $n^{\circ} 01$, de 10 de maio de 2016, concedeu um prazo de 12 meses, a partir da sua publicação, para que o processo de gestão de riscos esteja institucionalizado em todos os órgãos e entidades do poder executivo federal.

De forma complementar, verificou-se que não basta apenas implementar a gestão de riscos nas instituições, é fundamental que ela seja eficaz pois, de acordo com o International Federation of Accountants (IFAC, 2014), a gestão eficaz dos riscos permite que as entidades do setor público alcancem os seus objetivos de forma ética e legal.

Esse resultado se contrapõe a um estudo realizado por Christopher (2015, p. 959) junto aos principais executivos de auditoria nas universidades públicas Australianas, no qual $88,5 \%$ afirmaram que realizam avaliação no sistema de gerenciamento de risco da universidade.

No tocante ao conselho universitário - CONSUNI, órgão central da governança nas universidades públicas federais, a pesquisa revelou que $72,7 \%$ dos conselhos possuem membros externos e independentes, no entanto, 0 quantitativo é muito inferior em relação ao total de membros internos. Verificouse que os conselhos universitários possuem, em média, 50 membros, o que representa um quantitativo bem superior ao limite recomendado pelo Instituto Brasileiro de Governança Corporativa (IBGC, 2015), no qual sugere um número ímpar de conselheiros, entre cinco e onze, sendo que esse número pode variar conforme o setor de atuação, porte, complexidade das atividades e estágio do ciclo de vida da organização. 
De acordo com o art. 16, da lei $n^{\circ}$ 5.540, de 28 de novembro de 1968, o Conselho Universitário das universidades públicas federais deverá ser constituído por representantes dos diversos segmentos da comunidade universitária e da sociedade, observando o mínimo de setenta por cento de membros do corpo docente no total de sua composição.

Nesse contexto, percebe-se que a legislação vigente não está em consonância com as diretrizes do Instituto Brasileiro de Governança Corporativa - IBGC, no qual deve-se evitar a indicação de conselheiros internos na composição do conselho, de modo a promover a integridade do sistema de governança nas organizações.

Verificou-se que os conselhos universitários possuem, em média, 2 membros independentes e 1 membro externo em sua composição, sendo que a maioria dos membros independentes e externos é indicada pelos próprios membros internos que, posteriormente, são colocados em votação nas reuniões do CONSUNI.

Como instância interna de apoio a governança, a auditoria interna deverá estar vinculada ao conselho Universitário - CONSUNI, com a finalidade de proporcionar à unidade de auditoria interna uma maior abrangência e independência para a realização das suas atividades de controle, conforme diretrizes da Instrução Normativa $n^{\circ} 01$, de 06 de abril de 2001, emitida pela Secretaria Federal de Controle Interno.

De acordo com os resultados da pesquisa, somente $33,3 \%$ das auditorias internas estão vinculadas ao Conselho Universitário - CONSUNI. Metade das auditorias internas está vinculada ao Reitor da universidade, 15,2\% ao conselho curador e 3\% ao Pró-Reitor de Administração, o que resulta, dada a vulnerável independência, em uma fragilidade no sistema de governança dessas universidades.

Nesse contexto, e com o objetivo de medir a intensidade das opiniões da Alta administração em relação à atuação das auditorias internas na governança das universidades públicas federais, foi solicitada a manifestação de concordância ou discordância em relação a cada uma das afirmativas constantes da tabela 1, a seguir, segundo a graduação: (5) concorda muito, (4) concorda um pouco, (3) indeciso, (2) discordo um pouco e (1) discordo muito. 
Tabela 1

Análise descritiva das afirmativas relacionadas à atuação da auditoria interna.

\begin{tabular}{|c|c|c|c|c|c|c|}
\hline Seção C & 5 & 4 & 3 & 2 & 1 & $\begin{array}{l}\text { Média } \pm \\
\text { DP }\end{array}$ \\
\hline $\begin{array}{l}\text { A Auditoria Interna auxilia a } \\
\text { universidade na execução de suas } \\
\text { estratégias. }\end{array}$ & $\begin{array}{c}14 / 32 \\
(43,8 \%)\end{array}$ & $\begin{array}{c}12 / 32 \\
(37,5 \%)\end{array}$ & $\begin{array}{l}0 / 32 \\
(0 \%)\end{array}$ & $\begin{array}{c}6 / 32 \\
(18,8 \%)\end{array}$ & $\begin{array}{l}0 / 32 \\
(0 \%)\end{array}$ & $\begin{array}{l}4,06 \pm 1,11 \\
\quad(n=32)\end{array}$ \\
\hline $\begin{array}{l}\text { A Auditoria Interna possui uma } \\
\text { atuação flexível e alinhada com a } \\
\text { estratégia da universidade. }\end{array}$ & $\begin{array}{c}14 / 32 \\
(43,8 \%)\end{array}$ & $\begin{array}{c}12 / 32 \\
(37,5 \%)\end{array}$ & $\begin{array}{c}2 / 32 \\
(6,2 \%)\end{array}$ & $\begin{array}{c}4 / 32 \\
(12,5 \%)\end{array}$ & $\begin{array}{l}0 / 32 \\
(0 \%)\end{array}$ & $\begin{array}{l}4,12 \pm 1,01 \\
(n=32)\end{array}$ \\
\hline $\begin{array}{l}\text { A Auditoria Interna fornece visões } \\
\text { proativas }\end{array}$ & $\begin{array}{c}9 / 32 \\
(28,1 \%)\end{array}$ & $\begin{array}{c}13 / 32 \\
(40,6 \%)\end{array}$ & $\begin{array}{c}4 / 32 \\
(12,5 \%)\end{array}$ & $\begin{array}{c}5 / 32 \\
(15,6 \%)\end{array}$ & $\begin{array}{c}1 / 32 \\
(3,1 \%)\end{array}$ & $\begin{array}{r}3,75 \\
\quad(n=\end{array}$ \\
\hline $\begin{array}{l}\text { A Auditoria Interna atua de maneira } \\
\text { proativa }\end{array}$ & $\begin{array}{c}12 / 33 \\
(36,4 \%)\end{array}$ & $\begin{array}{c}10 / 33 \\
(30,3 \%)\end{array}$ & $\begin{array}{l}3 / 33 \\
(9,1 \%)\end{array}$ & $\begin{array}{c}5 / 33 \\
(15,2 \%)\end{array}$ & $\begin{array}{l}3 / 33 \\
(9,1 \%)\end{array}$ & $\begin{array}{l}3,7 \pm 1,36 \\
(n=33)\end{array}$ \\
\hline $\begin{array}{l}\text { A Alta administração considera a } \\
\text { Auditoria Interna uma instância } \\
\text { interna de apoio à governança da } \\
\text { universidade }\end{array}$ & $\begin{array}{c}18 / 33 \\
(54,5 \%)\end{array}$ & $\begin{array}{c}11 / 33 \\
(33,3 \%)\end{array}$ & $\begin{array}{l}1 / 33 \\
(3 \%)\end{array}$ & $\begin{array}{l}3 / 33 \\
(9,1 \%)\end{array}$ & $\begin{array}{l}0 / 33 \\
(0 \%)\end{array}$ & $\begin{array}{r}4,33 \\
1 \mathrm{n}=\end{array}$ \\
\hline $\begin{array}{l}\text { A Auditoria Interna contribui para } \\
\text { assegurar a integridade na } \\
\text { universidade. }\end{array}$ & $\begin{array}{c}21 / 33 \\
(63,6 \%)\end{array}$ & $\begin{array}{c}8 / 33 \\
(24,2 \%)\end{array}$ & $\begin{array}{l}1 / 33 \\
(3 \%)\end{array}$ & $\begin{array}{l}1 / 33 \\
(3 \%)\end{array}$ & $\begin{array}{c}2 / 33 \\
(6,1 \%)\end{array}$ & $\begin{array}{l}4,36 \pm 1,11 \\
(n=33)\end{array}$ \\
\hline $\begin{array}{lccc}\text { A Auditoria } & \text { Interna } & \text { possui } \\
\text { independência. } & & \\
\end{array}$ & $\begin{array}{c}28 / 33 \\
(84,8 \%)\end{array}$ & $\begin{array}{l}3 / 33 \\
(9,1 \%)\end{array}$ & $\begin{array}{l}1 / 33 \\
(3 \%)\end{array}$ & $\begin{array}{l}0 / 33 \\
(0 \%)\end{array}$ & $\begin{array}{l}1 / 33 \\
(3 \%)\end{array}$ & $\begin{array}{c}4,73 \pm 0,8 \\
(n=33)\end{array}$ \\
\hline $\begin{array}{l}\text { A Auditoria Interna avalia, de forma } \\
\text { eficaz, os controles internos da } \\
\text { gestão. }\end{array}$ & $\begin{array}{c}14 / 33 \\
(42,4 \%)\end{array}$ & $\begin{array}{c}10 / 33 \\
(30,3 \%)\end{array}$ & $\begin{array}{c}6 / 33 \\
(18,2 \%)\end{array}$ & $\begin{array}{c}2 / 33 \\
(6,1 \%)\end{array}$ & $\begin{array}{l}1 / 33 \\
(3 \%)\end{array}$ & $\begin{array}{l}4,03 \pm 1,07 \\
(n=33)\end{array}$ \\
\hline $\begin{array}{l}\text { A Auditoria Interna da universidade } \\
\text { tem auditado mais aspectos legais } \\
\text { (conformidade) do que aspectos } \\
\text { relacionados ao desempenho } \\
\text { (eficácia, eficiência } \\
\text { economicidade). }\end{array}$ & $\begin{array}{c}9 / 33 \\
(27,3 \%)\end{array}$ & $\begin{array}{c}20 / 33 \\
(60,6 \%)\end{array}$ & $\begin{array}{l}2 / 33 \\
(6,1 \%)\end{array}$ & $\begin{array}{l}1 / 33 \\
(3 \%)\end{array}$ & $\begin{array}{l}1 / 33 \\
(3 \%)\end{array}$ & $\begin{array}{c}4,06 \pm 0,86 \\
(n=33)\end{array}$ \\
\hline $\begin{array}{l}\text { A quantidade de auditores efetivos } \\
\text { é suficiente. }\end{array}$ & $\begin{array}{c}7 / 33 \\
(21,2 \%)\end{array}$ & $\begin{array}{c}10 / 33 \\
(30,3 \%)\end{array}$ & $\begin{array}{c}5 / 33 \\
(15,2 \%)\end{array}$ & $\begin{array}{c}10 / 33 \\
(30,3 \%)\end{array}$ & $\begin{array}{l}1 / 33 \\
(3 \%)\end{array}$ & $\begin{array}{c}3,36 \pm 1,22 \\
(n=33)\end{array}$ \\
\hline $\begin{array}{l}\text { O diretor/coordenador da unidade } \\
\text { de Auditoria Interna da universidade } \\
\text { possui os conhecimentos e as } \\
\text { habilidades necessárias para } \\
\text { conduzir com excelência os } \\
\text { trabalhos de auditoria. }\end{array}$ & $\begin{array}{c}20 / 33 \\
(60,6 \%)\end{array}$ & $\begin{array}{c}10 / 33 \\
(30,3 \%)\end{array}$ & $\begin{array}{l}0 / 33 \\
(0 \%)\end{array}$ & $\begin{array}{l}2 / 33 \\
(6,1 \%)\end{array}$ & $\begin{array}{l}1 / 33 \\
(3 \%)\end{array}$ & $\begin{array}{l}4,39 \pm 1 \\
(n=33)\end{array}$ \\
\hline $\begin{array}{l}\text { O (s) auditor (es) interno (s), de } \\
\text { maneira geral, possui (em) a } \\
\text { qualificação necessária. }\end{array}$ & $\begin{array}{c}15 / 32 \\
(46,9 \%)\end{array}$ & $\begin{array}{c}15 / 32 \\
(46,9 \%)\end{array}$ & $\begin{array}{l}0 / 32 \\
(0 \%)\end{array}$ & $\begin{array}{c}2 / 32 \\
(6,2 \%)\end{array}$ & $\begin{array}{l}0 / 32 \\
(0 \%)\end{array}$ & $\begin{array}{c}4,34 \pm 0,79 \\
(n=32)\end{array}$ \\
\hline $\begin{array}{l}\text { A Auditoria Interna da universidade } \\
\text { conta com uma infraestrutura } \\
\text { adequada. }\end{array}$ & $\begin{array}{c}14 / 32 \\
(43,8 \%)\end{array}$ & $\begin{array}{c}13 / 32 \\
(40,6 \%)\end{array}$ & $\begin{array}{c}4 / 32 \\
(12,5 \%)\end{array}$ & $\begin{array}{c}1 / 32 \\
(3,1 \%)\end{array}$ & $\begin{array}{l}0 / 32 \\
(0 \%)\end{array}$ & $\begin{array}{c}4,25 \pm 0,8 \\
(n=32)\end{array}$ \\
\hline $\begin{array}{l}\text { O conselho universitário da } \\
\text { universidade, ou a instância de } \\
\text { atribuição equivalente, aprova, de } \\
\text { forma periódica, O Plano de } \\
\text { Auditoria-PAINT. }\end{array}$ & $\begin{array}{c}23 / 32 \\
(71,9 \%)\end{array}$ & $\begin{array}{c}3 / 32 \\
(9,4 \%)\end{array}$ & $\begin{array}{c}3 / 32 \\
(9,4 \%)\end{array}$ & $\begin{array}{c}1 / 32 \\
(3,1 \%)\end{array}$ & $\begin{array}{c}2 / 32 \\
(6,2 \%)\end{array}$ & $\begin{array}{c}4,38 \pm 1,18 \\
(n=32)\end{array}$ \\
\hline
\end{tabular}


A Atuação da Auditoria Interna na Governança Pública: um Estudo Baseado na Visão da Alta Administração das Universidades Públicas Federais Brasileiras

\begin{tabular}{|c|c|c|c|c|c|c|}
\hline Seção C & 5 & 4 & 3 & 2 & 1 & $\begin{array}{c}\text { Média } \pm \\
\text { DP }\end{array}$ \\
\hline $\begin{array}{l}\text { Os relatórios da Auditoria Interna são } \\
\text { utilizados pelo conselho universitário, } \\
\text { ou a instância de atribuição } \\
\text { equivalente, para a tomada de } \\
\text { decisões estratégicas na } \\
\text { universidade. }\end{array}$ & $\begin{array}{c}10 / 32 \\
(31,2 \%)\end{array}$ & $\begin{array}{c}9 / 32 \\
(28,1 \%)\end{array}$ & $\begin{array}{c}6 / 32 \\
(18,8 \%)\end{array}$ & $\begin{array}{c}4 / 32 \\
(12,5 \%)\end{array}$ & $\begin{array}{l}3 / 32 \\
(9,4 \%)\end{array}$ & $\begin{array}{c}3,59 \pm 1,32 \\
(n=32)\end{array}$ \\
\hline $\begin{array}{l}\text { O conselho universitário da } \\
\text { universidade, ou a instância de } \\
\text { atribuição equivalente, monitora a } \\
\text { implementação } \\
\text { recomendações da auditoria } \\
\text { interna. }\end{array}$ & $\begin{array}{c}5 / 32 \\
(15,6 \%)\end{array}$ & $\begin{array}{c}17 / 32 \\
(53,1 \%)\end{array}$ & $\begin{array}{l}2 / 32 \\
(6,2 \%)\end{array}$ & $\begin{array}{c}5 / 32 \\
(15,6 \%)\end{array}$ & $\begin{array}{l}3 / 32 \\
(9,4 \%)\end{array}$ & $\begin{array}{l}3,51 \pm 1,22 \\
\quad(n=32)\end{array}$ \\
\hline $\begin{array}{l}\text { A Auditoria Interna da universidade } \\
\text { restringe a liberdade de atuação da } \\
\text { Alta administração. }\end{array}$ & $\begin{array}{l}3 / 32 \\
(9,4 \%)\end{array}$ & $\begin{array}{c}10 / 32 \\
(31,2 \%)\end{array}$ & $\begin{array}{c}6 / 32 \\
(18,8 \%)\end{array}$ & $\begin{array}{c}2 / 32 \\
(6,2 \%)\end{array}$ & $\begin{array}{c}11 / 32 \\
(34,4 \%)\end{array}$ & $\begin{array}{l}2,75 \pm 1,46 \\
\quad(n=32)\end{array}$ \\
\hline $\begin{array}{l}\text { A Auditoria Interna atua de maneira } \\
\text { coercitiva na universidade }\end{array}$ & $\begin{array}{c}3 / 32 \\
(9,4 \%)\end{array}$ & $\begin{array}{l}8 / 32 \\
(25 \%)\end{array}$ & $\begin{array}{c}5 / 32 \\
(15,6 \%)\end{array}$ & $\begin{array}{c}3 / 32 \\
(9,4 \%)\end{array}$ & $\begin{array}{c}13 / 32 \\
(40,6 \%)\end{array}$ & $\begin{array}{l}2,53 \pm 1,48 \\
(n=32)\end{array}$ \\
\hline
\end{tabular}

Fonte: Elaborada pelos autores

Analisou-se as opiniões dos respondentes em cada uma das afirmativas propostas, com a indicação, na última coluna da tabela, do total de respondentes, da média e do desvio padrão auferidos.

Com base nos resultados, verificou-se que $81,3 \%$ da Alta administração concorda que a auditoria interna auxilia a universidade na execução de suas estratégias, possuindo uma atuação flexível e alinhada com a estratégia da universidade, sendo que $43,8 \%$ dos respondentes concordam muito e $37,5 \%$ concordam um pouco com essa atuação.

Esse resultado positivo está em consonância com o estudo promovido pela Deloitte, no ano de 2015, sobre a estrutura e a maturidade da função de auditoria interna no Brasil, no qual menciona:

\begin{abstract}
Independentemente da forma de atuação a ser adotada, atualmente a função de auditoria interna deve se posicionar como uma função estratégica, que contribui para a preservação e geração de valor por meio das atividades de gestão de riscos, governança e conformidade dos processos, com foco nos objetivos estratégicos das organizações (Deloitte, 2015, p. 14).
\end{abstract}

Desse modo, a atuação da auditoria interna deve estar alinhada com os objetivos estratégicos da organização, de tal forma que esses objetivos representem um importante pilar no planejamento das ações de controle (IIA, 2012).

Constatou-se também que, aproximadamente, $67 \%$ da Alta administração considera a auditoria interna proativa na universidade, sendo que $36,4 \%$ dos respondentes concordam muito e 30,3\% concordam um pouco com essa atuação. O resultado evidencia que uma auditoria interna alinhada com as estratégias da universidade tende a atuar de forma preventiva, contribuindo para a identificação de possíveis riscos que possam obstar o alcance dos objetivos organizacionais.

Além de uma atuação proativa, alinhada com os objetivos estratégicos da universidade, a pesquisa revelou que $87,8 \%$ dos respondentes concordam que a 
auditoria interna contribui para assegurar a integridade na universidade, sendo que $63,6 \%$ concordam muito e $24,2 \%$ concordam um pouco com essa afirmação. Essa contribuição está em consonância com o pensamento de Marques (2014), no qual considera a auditoria interna um dos pilares da boa governança no setor público e, ao proporcionar avaliações, objetivas e imparciais, em relação à gestão dos recursos públicos, os auditores contribuem para assegurar a integridade nas organizações.

No tocante as avaliações objetivas e imparciais, verificou-se que, aproximadamente, $73 \%$ dos respondentes concordam que a auditoria interna avalia, de forma eficaz, os controles internos da gestão. Esse resultado mostra-se positivo, visto que, de acordo com Oliveira, Gomes e Machado (2015, p. 31), "os controles internos representam instrumentos de governança à disposição dos gestores, pois convergem para a consecução dos objetivos das instituições e seus programas".

De forma complementar, e segundo Castro (2015), os controles internos promovem a eficiência operacional da entidade, estimula a obediência e o respeito às políticas traçadas, protege os ativos e inibi a corrupção. Nesse âmbito, uma avaliação eficaz dos controles internos, pela auditoria interna, contribui para o alcance dos objetivos estratégicos da universidade.

Para garantir que os trabalhos dos auditores internos sejam realizados sem interferências em relação à determinação do escopo, execução, julgamento e na apresentação dos resultados, é primordial que as auditorias internas possuam independência e, nesse aspecto, $84,8 \%$ da Alta administração assevera que a auditoria interna detém essa independência na universidade.

Identificou-se também que, $87,8 \%$ dos respondentes consideram a auditoria interna uma instância interna de apoio à governança da universidade, sendo que $54,5 \%$ concordam muito e $33,3 \%$ concordam um pouco com essa afirmação. Esse resultado corrobora com as diretrizes do Tribunal de Contas da União (TCU,2014), no qual a auditoria interna integra-se como uma instância interna de apoio à governança pública.

As ações de controle da auditoria interna, integrantes do Plano Anual de Auditoria Interna - PAINT, devem ser aprovadas, de forma periódica, pelo Conselho Universitário, órgão central da governança nas universidades públicas federais, conforme determina o Art. $7^{\circ}$ da Instrução Normativa $n^{\circ} 24$, de 17 de novembro de 2015, proveniente da Controladoria Geral da União - CGU:

O Conselho de Administração ou a instância com atribuição equivalente ou, inexistindo, o dirigente máximo do órgão ou entidade, deverá aprovar o PAINT até o último dia útil do mês de dezembro do ano anterior ao de sua execução (BRASIL, 2015).

Desse modo, $81,3 \%$ dos respondentes concordam que o Conselho Universitário da universidade aprova, de forma periódica, o Plano Anual de Auditoria Interna - PAINT.

Convém mencionar que, ao final de cada trabalho realizado, a auditoria interna deverá enviar, pelo menos, um resumo dos relatórios de auditoria ao Conselho Universitário, conforme determinação do Art. 13 da Instrução Normativa $n^{\circ} 24$, de 17 de novembro de 2015: 
A Atuação da Auditoria Interna na Governança Pública: um Estudo Baseado na Visão da Alta Administração das Universidades Públicas Federais Brasileiras

\begin{abstract}
As unidades de auditoria interna, ao final de cada trabalho realizado, enviarão, pelo menos, o resumo dos relatórios de auditoria ao Conselho de Administração, ao Comitê de Auditoria, ao Conselho Fiscal ou órgão equivalente ou, em sua falta, ao dirigente máximo do órgão ou entidade (BRASIL, 2015).
\end{abstract}

Dessa forma, aproximadamente, $60 \%$ dos respondentes concordam que os relatórios de auditoria interna são utilizados pelo Conselho Universitário para a tomada de decisões estratégicas na universidade, sendo que $31,2 \%$ dos respondentes concordam muito e $28,1 \%$ concordam um pouco com esse aproveitamento.

Esse resultado mostra-se profícuo, tendo em vista que os relatórios de auditoria interna pressupõem avaliações, objetivas e imparciais, baseadas em uma quantidade suficiente de informações, coletadas em um determinado período de tempo, resultante de apropriadas e suficientes evidências, que abrange os processos de governança, gerenciamento de riscos e controles internos da gestão.

Em complemento, identificou-se que, aproximadamente, $69 \%$ dos respondentes concordam que $O$ Conselho Universitário monitora a implementação das recomendações dos auditores internos.

Em relação às afirmativas relacionadas aos recursos humanos, identificouse que, aproximadamente, $30 \%$ dos respondentes discordam que a quantidade de auditores efetivos existentes nas auditorias internas é suficiente e, esse resultado, aliado ao fato da maioria das universidades possuírem entre 2 a 4 auditores internos, bem como, da inexistência de uma política de distribuição de vagas de auditores internos proporcional ao montante orçamentário das universidades, constatou-se que a quantidade de auditores internos representa uma limitação das auditorias internas, principalmente nas universidades de grande porte, dado os expressivos valores orçamentários para controle, conforme citação, a seguir, do Pró-Reitor de Administração de uma universidade de grande porte da região Sudeste presente no grupo focal:

\footnotetext{
"Em todos os setores da universidade há carência de servidores, e na auditoria interna não é diferente. As atividades da universidade são complexas, envolve um orçamento expressivo, muito dinheiro, e com apenas quatro auditores internos não é possível dar conta de tudo, não há braço suficiente" (PRA 4 - universidade de grande porte região Sudeste).
}

Em contrapartida, mais de $90 \%$ dos respondentes concordam que o diretor/coordenador da unidade de auditoria interna possui os conhecimentos e as habilidades necessárias para conduzir com excelência os trabalhos de auditoria, sendo que $60,6 \%$ concordam muito e $30,3 \%$ concordam um pouco com essa competência. O resultado foi similar em relação aos auditores internos, visto que, mais de $90 \%$ dos respondentes concordam que os auditores internos, de maneira geral, possuem a qualificação necessária para o desenvolvimento dos trabalhos de auditoria interna, sendo que $46,9 \%$ dos respondentes concordam muito e 46,9\% concordam um pouco.

No tocante as afirmativas relacionadas à infraestrutura, mais de $83 \%$ dos respondentes concordam que a auditoria interna possui uma infraestrutura adequada para o desenvolvimento das suas atividades, sendo que 43,8\% 
concordam muito, 40,6\% concordam um pouco, $12,5 \%$ indecisos e $3,1 \%$ discordam um pouco.

Em referência aos processos e procedimentos de auditoria, identificou-se que, aproximadamente, $88 \%$ dos respondentes concordam que a auditoria interna da universidade tem auditado mais aspectos legais (conformidade) do que aspectos relacionados ao desempenho, sendo que $27,3 \%$ concordam muito e $60,6 \%$ concordam um pouco com esse posicionamento. Esse resultado indica que as auditorias internas das universidades públicas federais estão, prioritariamente, voltadas a comprovar a legalidade e legitimidade dos atos e fatos administrativos.

Registra-se também que, dentre todas as afirmativas propostas, duas afirmativas apresentaram médias inferiores a 3, são elas: a auditoria interna da universidade restringe a liberdade de atuação da Alta administração e, a auditoria interna atua de maneira coercitiva na universidade, com médias de 2,75 e 2,53, respectivamente. Esses valores de média apontam para a existência de uma polarização entre os respondentes e, como observado, aproximadamente, $40 \%$ da Alta administração concorda que a auditoria interna restringe a liberdade de atuação da Alta administração e, aproximadamente, $40 \%$ discordam com esse posicionamento.

Diante desse resultado, verificou-se que está presente em diversas universidades públicas federais o sentimento de auditoria interna com conduta de fiscalização, com um comportamento que restringe a autonomia da gestão, distante do que preceitua as diretrizes regidas pela Instrução Normativa Conjunta $n^{\circ} 01 / 2016$ e demais normas e regulamentos vigentes que exaltam o papel estratégico das auditorias internas nas organizações.

Além de uma atuação restritiva, aproximadamente, 35\% das universidades pesquisadas concordam que a auditoria interna opera de forma coercitiva na universidade, e esse resultado converge com o pensamento de Flozino e Silvério (2014, p. 137), "Alguns anos atrás o auditor possuía uma imagem marcante, era visto como autoritário aquele que apontava os erros e delatava-os, tanto que até os dias atuais ainda há algumas pessoas que evidenciam esta imagem".

Nesse contexto, e na busca de confirmar o entendimento entre os participantes do grupo focal, o moderador fez a seguinte pergunta: As auditorias internas possuem uma atuação estratégica ou uma atuação tradicional/fiscalizadora nas universidades públicas federais? Essa questão fomentou divergências entre os participantes, tendo em vista que na visão de alguns Pró-Reitores de Administração, a auditoria interna tem um papel estratégico na universidade, porém, ainda atuam de forma tradicional, fiscalizadora e coercitiva na universidade. Isso pode ser ilustrado pelas citações a seguir:

\footnotetext{
"Existem percepções diferentes da auditoria interna. Para os servidores a auditoria é intrusa, incomoda e não é bem-vinda. Em relação aos dirigentes da universidade, há o entendimento que a auditoria vem para ajudar, vem para alertar, mas posso afirmar que a cultura de uma auditoria estratégica não foi assimilada na minha universidade (PRA 1 - região Sudeste).
} 
A Atuação da Auditoria Interna na Governança Pública: um Estudo Baseado na Visão da Alta Administração das Universidades Públicas Federais Brasileiras

"Na minha percepção, a auditoria interna tem uma lógica estratégica na universidade, mas na prática, no dia-a-dia, a realidade é outra, os auditores têm uma atitude de polícia. Você tem, portanto, uma lógica e uma atitude que não estão em sintonia" (PRA 3 - região Nordeste).

"A auditoria interna tem uma atuação tradicional, rigorosa na universidade, muito voltada para a avaliação dos atos dos ordenadores de despesas. Uma ação estratégica é rara e somente acontece por demanda interna da gestão (PRA 2 - região Sul).

Com opiniões distintas, dois Pró-Reitores de Administração se manifestaram e relataram que, atualmente, a auditoria interna na universidade tem uma atuação mais estratégica, conforme pode ser demonstrado nas citações, a seguir:

\begin{abstract}
"A auditoria interna na minha universidade tem atuado em parceria com a Alta administração, tanto é que hoje a função principal da auditoria interna é a consultoria, principalmente em assuntos relacionados com a mitigação de riscos" (PRA 2 - região Norte).

"Um tempo atrás eu tinha a visão que a auditoria vinha para atrapalhar, para exigir, para fiscalizar e inclusive, uma fiscalização punitiva, no sentido de expor o órgão, expor o gestor. Hoje percebo que mudou muito o perfil de trabalho da auditoria interna. Ela tem atuado de forma preventiva, ajudando o gestor a prevenir os riscos. Atualmente, a percepção da auditoria interna é muito positiva, de tal forma que ela contribui muito para atingir os objetivos, a missão da instituição" (PRA 1 - Centro-Oeste).
\end{abstract}

No intuito de explicar essa imagem, Marçola (2011) aduz que muitos gestores públicos desconhecem a missão e os objetivos das auditorias internas e, de forma equivocada, visualizam a auditoria interna como um problema, uma área com foco controlador e punitivo.

\title{
5 CONCLUSÕES
}

O Brasil está vivenciando um momento de intenso debate sobre o combate à corrupção, e ao mesmo tempo, a atual conjuntura social e econômica brasileira demanda mudanças na atuação do Estado, especialmente à forma de administrá-lo. Na atualidade, observa-se que a gestão pública ainda é marcada pelo excesso de formalismo, pela ineficiência na prestação de serviços públicos e pelo desprimor da sociedade como um todo.

Nesse contexto, a governança emerge com o propósito de direcionar, avaliar e monitorar a atuação da gestão pública, tendo como base os princípios da equidade, prestação de contas (accountability), transparência e valorização da ética, na busca de atender as necessidades e expectativas da sociedade.

Uma importante instância interna de apoio à governança nos órgãos e entidades da administração pública é a auditoria interna, que tem como finalidade assegurar o alinhamento da atuação dos agentes (gestores públicos) aos interesses do principal (sociedade), de forma a atender aos requisitos de boas práticas de governança pública.

No tocante à governança nas universidades públicas federais, os resultados do estudo evidenciaram que as diretrizes para boas práticas de governança corporativa emanadas do Instituto Brasileiro de Governança 
Corporativa (IBGC, 2015), não são plenamente adotadas pelas universidades públicas federais, tendo em vista que muitas das determinações são expressas por intermédio de leis e regulamentos.

Em adendo, verificou-se que a maioria das universidades pesquisadas não possui o Comitê de Governança, Riscos e Controles, conforme diretrizes da Instrução Normativa Conjunta n 01, do dia 10 de maio de 2016, proveniente da Controladoria Geral da União, que determina a adoção de diversas medidas com vistas à sistematização de práticas relacionadas à governança, gestão de riscos e controles internos.

Além da inexistência do Comitê de Governança, Riscos e Controles na maioria das universidades pesquisadas, identificou-se a ausência de gestão de riscos pela Alta administração e, nesse cenário, constata-se uma situação de alta vulnerabilidade na gestão dessas universidades, tendo em vista que a gestão estratégica da universidade está intimamente relacionada com 0 gerenciamento do portfólio de riscos da organização.

Em relação ao posicionamento das unidades de auditoria interna na estrutura de governança, verificou-se que apenas 33,3\% das auditorias internas estão vinculadas ao Conselho Universitário, 48,5\% estão vinculadas ao Reitor, 15,2\% ao Conselho Curador e 3\% ao Pró-Reitor de Administração. Esse resultado reforça a fragilidade existente na estrutura de governança das universidades públicas federais, visto que, de acordo com a Instrução Normativa nº 01, de 06 de abril de 2001, emitida pela Secretaria Federal de Controle Interno, a unidade de auditoria interna deverá estar subordinada ao Conselho de Administração ou a órgão de atribuições equivalentes, que no caso das universidades públicas federais corresponde ao Conselho Universitário - CONSUNI, e essa vinculação têm por objetivo proporcionar à unidade de auditoria interna um posicionamento suficientemente elevado de modo a permitir-lhe desincumbir-se de suas responsabilidades com abrangência e maior independência, assegurando dessa maneira, sua atuação efetiva como instância interna de apoio a governança.

Sugere-se que novas pesquisas sejam realizadas envolvendo não apenas a visão da Alta administração (Reitores, Vice-Reitores, Pró-Reitores de Administração e Pró-Reitores de Planejamento), mas também a opinião dos próprios auditores das unidades de auditoria interna, dos auditores de finanças e controle do Ministério da Transparência, Fiscalização e Controle - MTFC, dos auditores de controle externo do Tribunal de Contas da União - TCU e dos membros internos e externos dos Conselhos Universitários das universidades públicas federais ampliaria o campo de investigação da pesquisa.

\section{REFERÊNCIAS}

Barros, A. J. da S., \& Lehfeld, N. A. de S. (2007). Fundamentos de Metodologia Científica ( $3^{\circ}$ ed). São Paulo: Pearson Prentice Hall.

Batista, D. G. (2011). Manual de Controle e Auditoria: Com Ênfase na Gestão de Recursos Públicos ( $1{ }^{\circ}$ ed). São Paulo: Saraiva. 
A Atuação da Auditoria Interna na Governança Pública: um Estudo Baseado na Visão da Alta Administração das Universidades Públicas Federais Brasileiras

Brasil. Instrução Normativa Conjunta no 01, de 10 de maio de 2016. Dispõe sobre controles internos, gestão de riscos e governança no âmbito do poder executivo federal.

Brasil. Instrução Normativa n 01, de 06 de abril de 2001. Define diretrizes, princípios, conceitos e aprova normas técnicas para a atuação do Sistema de Controle Interno do Poder Executivo Federal.

Brasil. Lei no 5.540, de 28 de novembro de 1968. Fixa normas de organização e funcionamento do ensino superior e sua articulação com a escola média, e dá outras providências.

Brasil. Tribunal de Contas da União. (2014). Referencial básico de governança aplicável a órgãos e entidades da administração pública / Tribunal de Contas da União. Versão 2-Brasília: TCU, Secretaria de Planejamento, Governança e Gestão.

Caregnato, R. C. A., \& Mutti, R. (2006). Pesquisa qualitativa: Análise de discurso versus análise de conteúdo. Texto \&amp; Contexto - Enfermagem, 15(4), 679684. DOI:10.1590/S0104-07072006000400017

Castro, D. P. de. (2015). Auditoria, Contabilidade e Controle interno no Setor Público: Integração das áreas do ciclo de gestão: planejamento, orçamento, finanças, contabilidade e auditoria e organização dos controles internos, como suporte à Governança Corporativa (6० ed). São Paulo: Atlas.

Cavalcante, M. C. N., \& Luca, M. M. M. D. (2013). Controladoria como Instrumento de Governança no Setor Público. Revista de Educação e Pesquisa em Contabilidade (REPeC), 7(1). DOI: 10.17524/repec.v7i1.138

Chaves, R. S. (2011). Auditoria e controladoria no setor público: Fortalecimento dos controles internos: com jurisprudência do TCU (2० ed). Curitiba: Juruá.

Christopher, J. (2015). Internal audit: Does it enhance governance in the Australian public university sector? Educational Management Administration \& Leadership, 43(6), 954-971. DOI: 10.1177/1741143214543206

Deloitte. (2015). Auditoria Interna no Brasil: Função estratégica para a geração de valor nas organizações. Deloitte.

Flozino, A. V. B. (2014). Auditoria interna e sua importância para micro e pequenas empresas. Revista interatividade, 2(2).

Gil, A. C. (2010). Métodos e técnicas de pesquisa social (60 ed). São Paulo: Atlas.

IBGC. (2015). Código Brasileiro de Governança Corporativa: Companhias Abertas / Grupo de Trabalho Interagentes; coordenação Instituto Brasileiro de Governança Corporativa (5॰ ed). São Paulo: IBGC. 
IFAC. (2014). International Framework: Good Governance in the Public Sector, Executive Summary.

IIA. (2012). International Standards for the Professional Practice of Internal Auditing.

IIA. ([s.d.]). Estrutura Internacional de Práticas Profissionais.

IIARF. (2009). Internal Audit Capability Model (IA-CM) for the Public Sector.

Maki, T., DeLoach, J. W., Beasley, M. S., Jackson, A. J., DeFoor, J. W., Jameson, S. E., ... Martens, F. J. (2004). Enterprise Risk Management: Integrated Framework. PricewaterhouseCoopers LLP.

Marçola, C. (2014). Auditoria interna como instrumento de controle social na administração pública. Revista do Serviço Público, 62(1), 75-87. DOl: 10.21874/rsp.v62i1.62

Marques, M. C. C. (2014). Corporate governance e auditoria do setor público em Portugal: Enfoque nas instituições de ensino superior públicas. XVI Encuentro AECA. Apresentado em Portugal. Portugal.

Oliveira, A. J. S. J., Gomes, A. R., \& Machado, G. V. (2015). Metodologia de auditoria com foco em processo e risco | Revista do TCU. (132). Recuperado de https://revista.tcu.gov.br/ojs/index.php/RTCU/article/view/249

Peter, M. da G. A., \& Machado, M. V. V. (2014). Manual de auditoria governamental (2a. Ed.). São Paulo: Editora Atlas S.A.

Rodrigues, J. A., \& Mendes, G. de M. (2004). Governança corporativa: Estratégia para geração de valor. Rio de Janeiro: Qualitymark.

Sá, A. L. de. (2002). Curso de Auditoria (100 ed). São Paulo: Atlas.

Silva, M. M. (2012). Curso de auditoria Governamental: De acordo com as Normas Internacionais de Auditoria Pública aprovadas pela INTOSAI (2० ed). São Paulo: Atlas.

Streit, R. E., \& Klering, L. R. (2004). Governança pública sob a perspectiva dos sistemas complexos. Encontro de Administração Pública e Governança EnAPG. Apresentado em Rio de Janeiro. Rio de Janeiro. 


\section{CONTRIBUIÇÕES DOS AUTORES}

\begin{tabular}{|l|c|c|}
\hline \multicolumn{1}{|c|}{ Contribuição } & $\begin{array}{c}\text { Douglas Renato } \\
\text { Pinheiro }\end{array}$ & $\begin{array}{c}\text { Eduardo de } \\
\text { Camargo Oliva }\end{array}$ \\
\hline $\begin{array}{l}\text { 1. Idealização e concepção do assunto e tema da } \\
\text { pesquisa }\end{array}$ & $\checkmark$ & \\
\hline 2. Definição do problema de pesquisa & $\checkmark$ & \\
\hline 3. Desenvolvimento da Plataforma Teórica & $\checkmark$ & \\
\hline $\begin{array}{l}\text { 4. Delineamento da abordagem metodológica da } \\
\text { pesquisa }\end{array}$ & & \\
\hline 5. Coleta de dados & $\checkmark$ & \\
\hline 6. Análises e interpretações dos dados coletados & $\checkmark$ & $\checkmark$ \\
\hline 7. Conclusões da pesquisa & $\checkmark$ & $\checkmark$ \\
\hline 8. Revisão crítica do manuscrito & & $\checkmark$ \\
\hline $\begin{array}{l}\text { 9. Redação final do manuscrito, conforme as normas } \\
\text { estabelecidas pela Revista. }\end{array}$ & & \\
\hline 10. Orientação & & \\
\hline
\end{tabular}

